\title{
Excavated farmland with plastic mulching as a strategy in saving water and controlling soil salinization in dryland agricultural areas
}

\author{
Zengming $\mathrm{Ke}^{1}$, Xiaoli $\mathrm{Liu}^{2}$, Lihui $\mathrm{Ma}^{2}$, Qinge Dongle ${ }^{3}$, Feng $\mathrm{JiaO}^{2}$, and Zhanli Wang ${ }^{4}$ \\ ${ }^{1}$ Institute of Soil and Water Conservation Northwest A \& F University \\ ${ }^{2}$ Northwest A\&F University \\ ${ }^{3}$ Northwest Agriculture and Forestry University \\ ${ }^{4}$ State Key Laboratory of Soil Erosion and Dryland Farming on the Loess Plateau, \\ Institute of Soil and Water Conservation
}

January 8, 2022

\begin{abstract}
Water shortage and soil salinization in gully farmland comprising sediment deposited farmland (SF) and excavated farmland (EF) have become a widespread concern in the loess hilly region. A two-year field experiment was conducted to assess the soil water content (SWC) and salt content (SSC) and their effect on the spring maize yield and water use efficiency in SF and EF. Eight treatments comprising flat cropping without mulching (1), ridge planting without mulching (2), ridge planting with plastic mulching (3), and ridge planting with straw mulching (4) were tested in the SF and EF plots, respectively. The results showed that the yield was higher in SF than EF, whereas the water use efficiency was significantly higher in EF because the bottom water flux was $117.4 \%$ higher in $\mathrm{SF}$ than $\mathrm{EF}(\mathrm{P}<0.01)$. A significant positive correlation was found between the average SWC and yield $(\mathrm{P}<0.01)$, thereby indicating that the yield was severely limited by the SWC. Thus, the higher water use efficiency in EF has important implications for alleviating water scarcity during agricultural production in this region. The risk of soil salinization was decreased greatly by treatment 3 where the SSC was decreased in EF and SF were $0.09 \mathrm{~g}$ kg-1 and $0.08 \mathrm{~g} \mathrm{~kg}-1$, respectively. In addition, treatment 3 had the most significant impacts on the yield and water use efficiency. Our study provided appropriate land type and effective tillage measure for the sustainable development in dryland agricultural areas.
\end{abstract}

\section{Hosted file}

Manuscript.docx available at https://authorea.com/users/454541/articles/552139-excavatedfarmland-with-plastic-mulching-as-a-strategy-in-saving-water-and-controlling-soilsalinization-in-dryland-agricultural-areas 

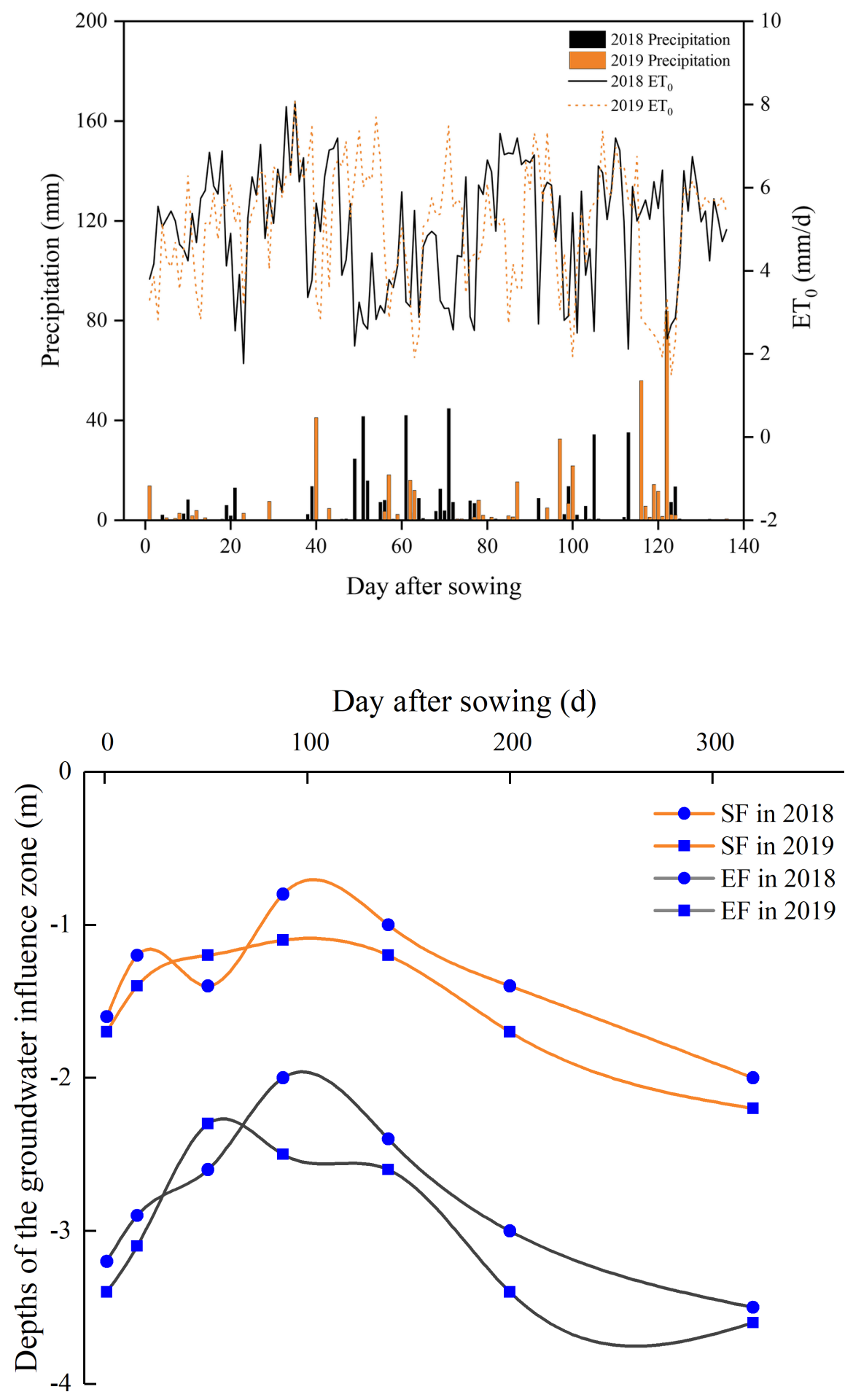
(a) Flat cropping (treatment 1)

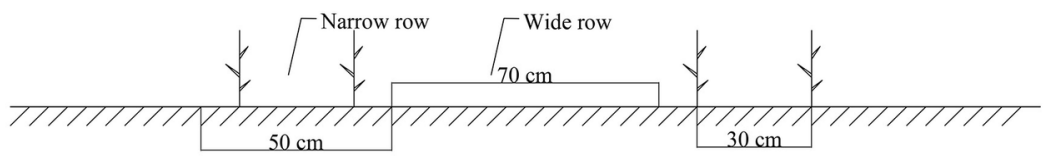

(b) Ridge planting (treatment 2, 3 and 4)
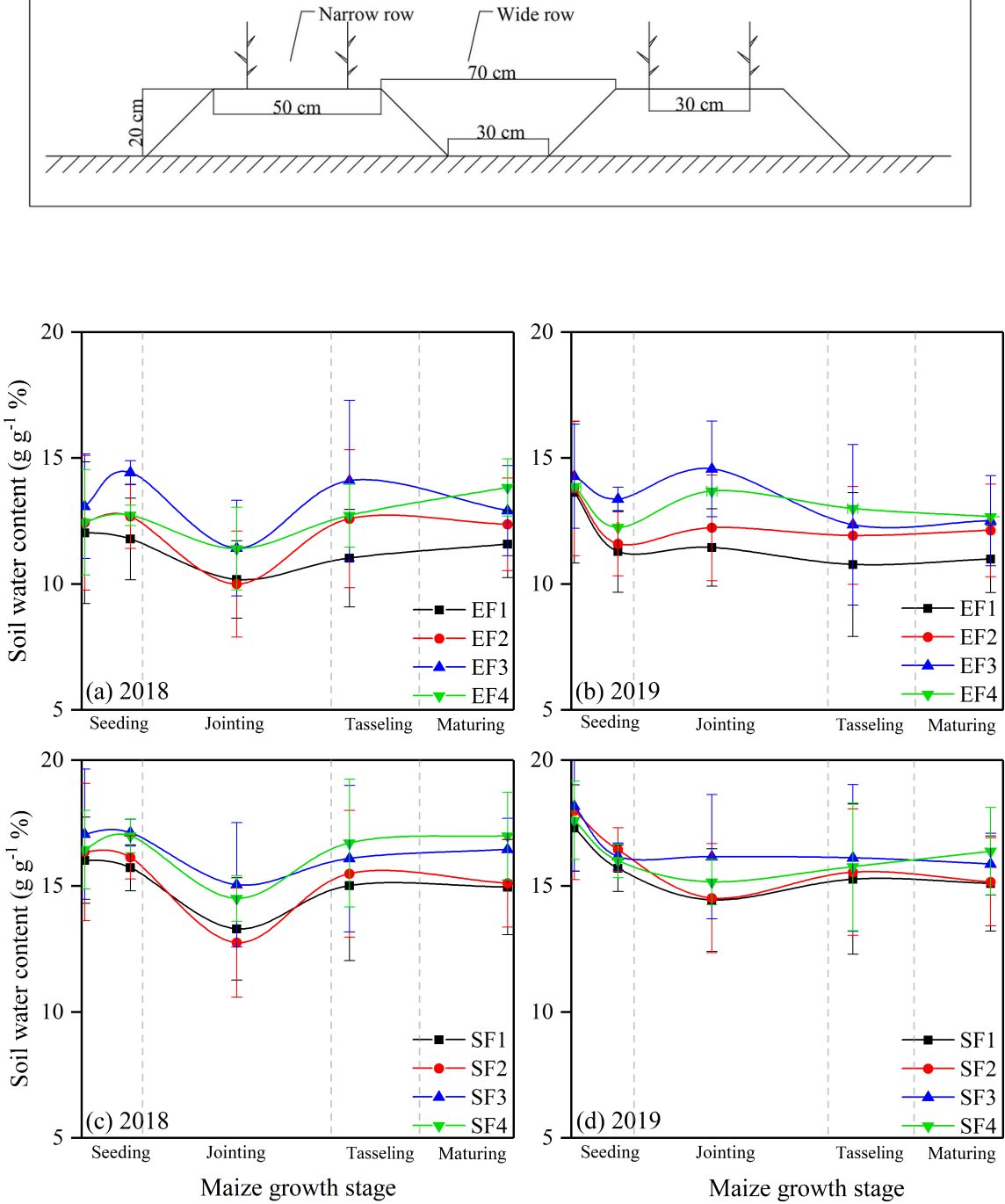

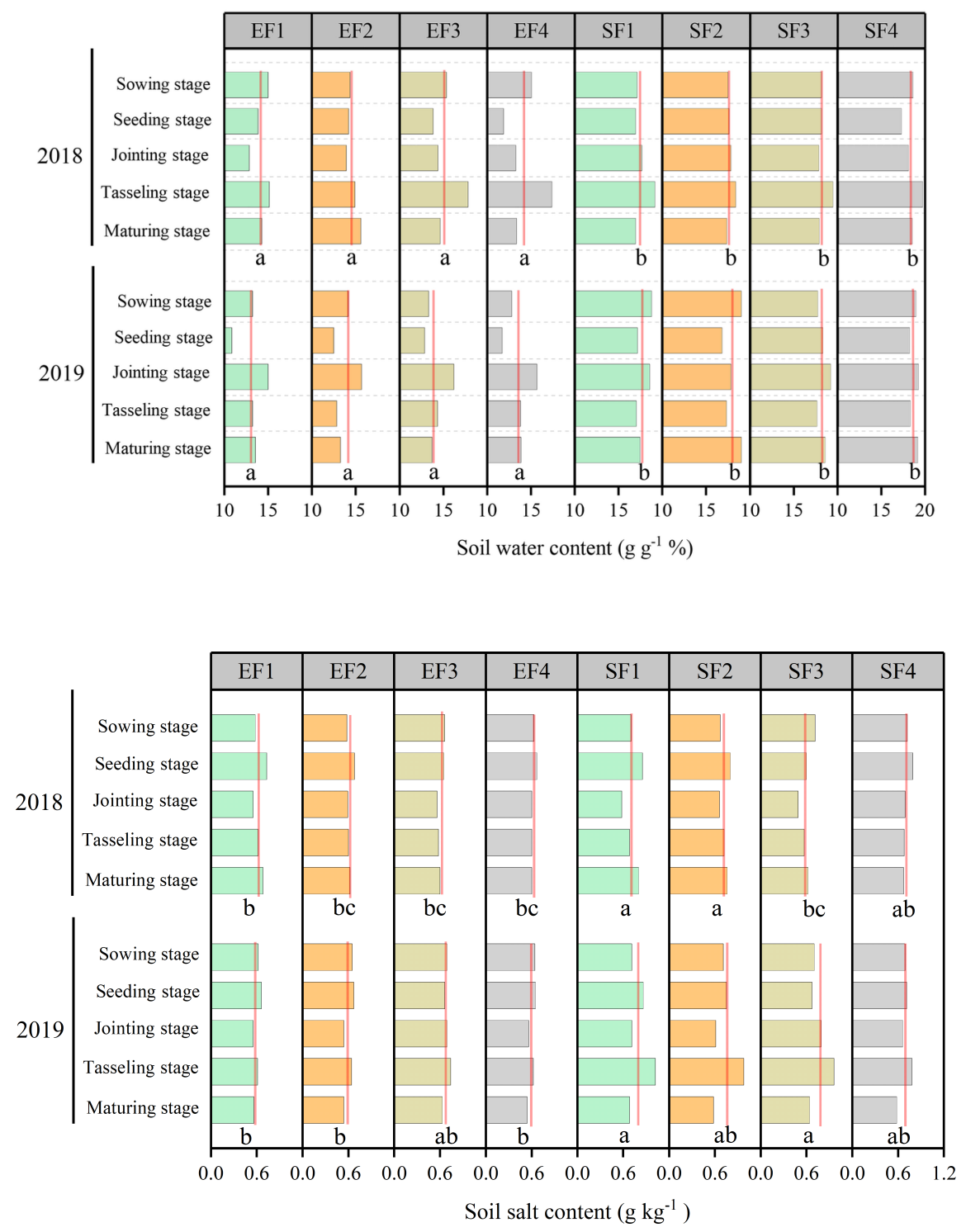

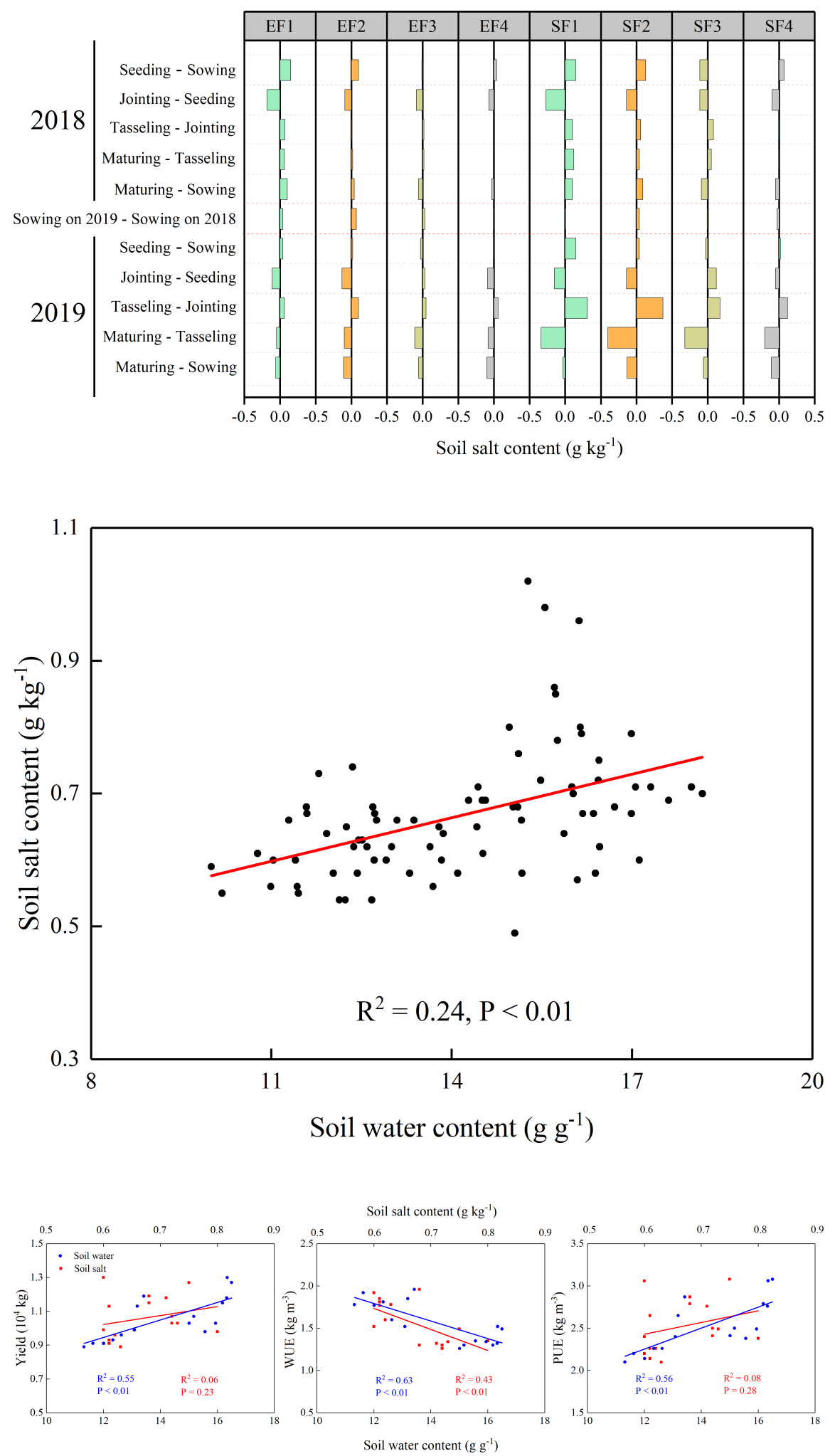